\title{
BMJ Open Is selective prenatal iron prophylaxis better than routine prophylaxis: final results of a trial (PROFEG) in Maputo, Mozambique
}

\author{
Elina Hemminki, ${ }^{1}$ Bright I Nwaru, ${ }^{2,3}$ Graca Salomé, ${ }^{4}$ Saara Parkkali, ${ }^{1}$ \\ Fatima Abacassamo, ${ }^{5}$ Orvalho Augusto, ${ }^{5}$ Julie Cliff, ${ }^{5}$ Elena Regushevskaya, ${ }^{1}$ \\ Martinho Dgedge, ${ }^{6}$ Cesar Sousa, ${ }^{5}$ Baltazar Chilundo ${ }^{5}$
}

To cite: Hemminki E, Nwaru BI, Salomé G, et al. Is selective prenatal iron prophylaxis better than routine prophylaxis: final results of a trial (PROFEG) in Maputo, Mozambique. BMJ Open 2016;6:e011280. doi:10.1136/bmjopen-2016011280

- Prepublication history and additional material is available. To view please visit the journal (http://dx.doi.org/ 10.1136/bmjopen-2016011280).

Received 26 January 2016 Revised 19 April 2016 Accepted 18 May 2016

CrossMark

For numbered affiliations see end of article.

Correspondence to Dr Elina Hemminki; Elina.hemminki@thl.fi

\section{ABSTRACT}

Objective: To compare routine versus selective (ie, screening and treatment for anaemia) prenatal iron prophylaxis in a malaria-endemic and HIV-prevalent setting, an extended analysis including previously missing data.

Design: A pragmatic randomised controlled clinical trial.

Setting: 2 health centres in Maputo, Mozambique. Participants: Pregnant women ( $\geq 18$ years old; non-high-risk pregnancy) were randomly allocated to routine iron $(n=2184)$ and selective iron $(n=2142)$ groups.

Interventions: In the routine group, women received $60 \mathrm{mg}$ ferrous sulfate plus $400 \mu \mathrm{g}$ folic acid daily. In the selective group, women received $1 \mathrm{mg}$ of folic acid daily and haemoglobin $(\mathrm{Hb})$ screening at each visit; with low $\mathrm{Hb}$ (cut-off $9 \mathrm{~g} / \mathrm{dL}$ ) treatment (120 mg+800 $\mu \mathrm{g}$ of folic acid daily) for a month.

Outcome measures: Primary outcomes: preterm birth, low birth weight; secondary outcomes: selfreported malaria, labour complications, caesarean section, perinatal death, woman's death. Nurses collected pregnancy data. Birth data were abstracted from hospital records for $52 \%$ of women and traced using various methods and linked with probabilistic matching for $24 \%$. Women's deaths were collected from death registers.

Results: Birth data were available for 3301 (76\%) of the women. Outcomes were similar in the two groups: preterm births $(27.1 \%$ in the selective vs $25.3 \%$ in the routine group), low birthweight infants $(11.0 \%$ vs $11.7 \%)$, perinatal deaths $(2.4 \%$ vs $2.4 \%)$ and caesarean sections ( $4.0 \%$ vs $4.5 \%)$. Women's deaths during pregnancy or $<42$ days postpartum were more common in the selective group $(0.8 \%$ among the two best matched women) than in the routine group $(0.4 \%)$. Extra deaths could not be explained by the cause of death, Hb level or HIV status at recruitment.

Conclusions: Birth outcomes were similar in the two iron groups. There might have been more women's deaths in the selective iron group, but it is

\section{Strengths and limitations of this study}

- The study achieved comparability of the groups due to randomisation and a large number of participants.

- Results are generalisable to the local prenatal care; since the trial was made in real circumstances, it included most women entering the care sites, and it allowed treatment of anaemia.

- By the original data collection method, many women were lost to follow-up, leading to data completion from routine records with fewer outcomes and matching uncertainties.

- Interventions may be weak due to short exposure and unknown compliance; higher dose in the treatment in the selective iron group confuses the evaluation of iron prophylaxis.

unclear whether this was due to the intervention, other factors or chance finding.

Trial registration number: NCT00488579.

\section{BACKGROUND}

Globally, prophylactic iron supplementation has proven to be effective in preventing irondeficiency anaemia, particularly in pregnant women and children, who are usually at greater risk. ${ }^{1-3}$ However, benefits for outcomes of pregnancy and childbirth are unclear. ${ }^{4-7} \mathrm{~A}$ recent meta-analysis reported a $7-29 \%$ decrease in the risk of low birth weight, but no effect on preterm birth, duration of gestation and birth length with iron supplementation. ${ }^{8}$ Two trials published since that review bring further light to the issue, but do not resolve the question of the benefits of iron supplementation in malaria and HIV-endemic areas. ${ }^{9}{ }^{10}$ A trial from urban Tanzania among non-anaemic, HIV-negative pregnant women did not show harm in regard to malaria 
infection, and did not find any benefits in infant outcomes. ${ }^{9}$ Similarly a trial from rural Kenya with malaria prophylaxis did not show any harm in regard to malaria, but the children had higher birth weight. ${ }^{10}$

Infectious agents require iron for replication and there is some evidence linking iron supplements to infections, such as malaria and diarrhoea. ${ }^{11-13}$ In many developing countries, infections such as malaria and HIV are a leading cause of maternal and child morbidity and mortality. ${ }^{14} 15$ Consequently, the implications of routine prenatal iron prophylaxis for maternal and child health in these settings remain uncertain. Among young children, iron supplementation plus folic acid versus placebo increased the risk of hospitalisation and mortality in a malaria-endemic setting. ${ }^{16}$

To find out whether prenatal iron prophylaxis improves pregnancy and birth outcomes in a setting of endemic malaria and high prevalence of HIV, we carried out a pragmatic randomised controlled trial (PROFEG) in Maputo, Mozambique, comparing routine iron prophylaxis throughout pregnancy to screening and treatment for anaemia. ${ }^{17}$ We have previously reported preliminary results of the trial, which showed that routine iron prophylaxis conferred no advantage over screening and treatment for anaemia. ${ }^{18}$ By the original data collection method, $40 \%$ of births were missing. ${ }^{18}$ We traced more women by various complementary methods, and report birth outcomes after tracing and present data of deaths obtained by record linkage to death registers.

\section{MATERIALS AND METHODS \\ Ethical approval}

A positive statement was obtained from the National Research and Development Centre for Welfare and Health (STAKES), Helsinki, Finland (Dno 2571/501/ 2007). Oral and written informed consent was obtained from participating women. The trial is registered at ClinicalTrials.gov, number NCT00488579.

\section{Study design}

Details of the PROFEG trial have been presented in earlier papers. ${ }^{17} 18$ Here we only describe the main characteristics and tracing of women lacking data from the original data collection, giving more details in the online supplementary file. PROFEG was a pragmatic randomised controlled trial comparing the effects of two iron administration policies on maternal and child health in Maputo, Mozambique, which recruited women from two health centres, $1^{\circ}$ de Maio in Maputo City (during November 2006-October 2008) and Machava 2 in Maputo Province (June 2007-October 2008). Both centres are located in areas endemic for malaria with seasonal variation. ${ }^{19}$

\section{Recruitment, randomisation and sample size estimation}

Study nurses, trained by the project, invited women attending their first prenatal visit into the trial, excluding women with high-obstetric risk and those $<18$ years. ${ }^{18}$ Women were informed of the trial during collective health education sessions and then recruited during individual prenatal consultations

Women were randomly assigned to one of the trial arms using sequential random numbers generated with a probability of $50 \%$. Stata statistical software was used to generate sequential random numbers separately for the two centres. Women's study numbers were enclosed in sealed and numbered opaque envelopes, which contained a study identification card (yellow for the routine iron group and pink for the selective, $10 \times 20 \mathrm{~cm}$ ) and the informed consent form.

Since we had no reliable baseline estimates of birth outcomes in Maputo, in calculating the sample size we assumed different estimates of the primary outcomes, with power $(85 \%$ and $90 \%)$, a significance level of $5 \%$ and the size of the difference to be detected $(20 \%$ and $30 \%)$. On the basis of these, we estimated a sample size of 2000 women in each trial arm to be enough to measure clinically meaningful effects.

\section{Interventions and adherence}

Women in the routine iron supplementation group $(\mathrm{n}=2184)$ received iron folate prophylaxis $(60 \mathrm{mg}$ ferrous sulfate plus $400 \mu \mathrm{g}$ folic acid daily) from the first to the last prenatal visit. Women in the selective group $(\mathrm{n}=2142)$ received $1 \mathrm{mg}$ of folic acid per day. At each visit, nurses measured women's haemoglobin $(\mathrm{Hb})$ by a rapid $\mathrm{Hb}$ measure, HemoCue $\mathrm{Hb} 201+$. If $\mathrm{Hb}$ was below the cut-off $<9 \mathrm{~g} / \mathrm{dL}$, women received a double dose of iron $(120 \mathrm{mg}+800 \mu \mathrm{g}$ of folic acid per day) for a month to treat anaemia. If anaemia did not disappear, the treatment was continued.

$\mathrm{Hb}$ was measured at the first visit from almost all of the women in the selective group (98\%) (table 1), as well as in subsequent visits. ${ }^{17}$ The proportions of women having one, two and three subsequent visits were $68 \%$, $49 \%$ and $33 \%$. Women were asked some additional questions related to compliance. ${ }^{20}$ Overall adherence to the trial (number of prenatal visits and intake of iron and folic acid tablets) was above the 50th centile. ${ }^{20}$

\section{Outcome measures}

The primary outcomes were preterm birth $(<37$ weeks of gestation) and low birth weight $(<2500 \mathrm{~g})$. Secondary outcomes were perinatal deaths; complications during labour; ${ }^{18}$ symptoms suggestive of malaria (fever, headache, cold/chills, nausea/vomiting and body aches during pregnancy); and self-reported malaria during pregnancy (at each visit, the woman was asked for diagnosed malaria since her last visit) ${ }^{18}$ caesarean section delivery; and women's death during pregnancy or $\leq 365$ days postpartum. Complications during labour were not available and perinatal deaths were poorly available from the traced data. 
Table 1 Characteristics of women by availability of birth data and study group, numbers (proportions \%) or means (SDs) at recruitment visit

\begin{tabular}{|c|c|c|c|c|}
\hline \multirow[b]{2}{*}{ Characteristics } & \multicolumn{2}{|c|}{ Birth data, $n=3301$} & \multicolumn{2}{|c|}{ No birth data, $n=1025$} \\
\hline & $\begin{array}{l}\text { Selective iron } \\
(n=1642)\end{array}$ & $\begin{array}{l}\text { Routine iron } \\
(n=1659)\end{array}$ & $\begin{array}{l}\text { Selective iron } \\
(n=500)\end{array}$ & $\begin{array}{l}\text { Routine iron } \\
(n=525)\end{array}$ \\
\hline Maternal age, mean (SD) years & $24.7(5.5)$ & $24.6(5.3)$ & $25.9(5.6)$ & $24.9(5.8)$ \\
\hline \multicolumn{5}{|l|}{ Maternal age (categorised), n (\%) (years) } \\
\hline$<20$ & $277(16.9)$ & $298(18.0)$ & $80(16.0)$ & $92(17.5)$ \\
\hline $20-24$ & $661(40.3)$ & $643(38.8)$ & $198(39.6)$ & 199 (37.9) \\
\hline $25-29$ & $380(23.1)$ & $389(23.4)$ & $122(24.4)$ & $121(23.0)$ \\
\hline $30-34$ & $205(12.5)$ & $229(13.8)$ & $53(10.6)$ & $67(12.8)$ \\
\hline$\geq 35$ & $105(6.4)$ & $89(5.4)$ & $41(8.2)$ & $43(8.2)$ \\
\hline Missing & $14(0.9)$ & $11(0.7)$ & $6(1.2)$ & $3(0.6)$ \\
\hline $\begin{array}{l}\text { Haemoglobin by HemoCue (g/dL), } \\
\text { mean (SD) }\end{array}$ & $9.6(1.7)$ & & $9.7(1.8)$ & \\
\hline \multicolumn{5}{|l|}{ Haemoglobin by HemoCue (g/dL), n (\%) } \\
\hline$<7.0$ & $107(6.5)$ & & $34(6.8)$ & \\
\hline $7.0-8.90$ & $414(25.2)$ & & $121(24.2)$ & \\
\hline $9.0-9.90$ & $391(23.8)$ & & $121(24.2)$ & \\
\hline $10.0-10.90$ & $356(21.7)$ & & $106(21.1)$ & \\
\hline $11.0-11.90$ & $231(14.1)$ & & 67 (13.4) & \\
\hline$\geq 12.0$ & $126(7.7)$ & & $48(9.6)$ & \\
\hline Not measured & $17(1.0)$ & & $3(0.6)$ & \\
\hline \multicolumn{5}{|l|}{ Iron given at recruitment, $\mathrm{n}(\%)$} \\
\hline No & $1088(66.3)$ & $13(0.8)$ & $333(66.6)$ & $1(0.2)$ \\
\hline Yes & 545 (33.2) & $1642(99.0)$ & $163(32.6)$ & $522(99.4)$ \\
\hline Missing & $9(0.6)$ & $4(0.2)$ & $4(0.8)$ & $2(0.4)$ \\
\hline Gestational age, mean (SD) weeks & $21.6(5.9)$ & $21.7(5.7)$ & $20.4(6.1)$ & $20.8(5.9)$ \\
\hline \multicolumn{5}{|c|}{ Gestational age (categorised), $\mathrm{n}(\%)$ weeks } \\
\hline$<16$ & $310(18.9)$ & $276(16.6)$ & $124(24.8)$ & $122(23.2)$ \\
\hline $17-20$ & $352(21.4)$ & $388(23.4)$ & $121(24.2)$ & $113(21.5)$ \\
\hline $21-26$ & $567(34.5)$ & $554(33.4)$ & $138(827.6)$ & 169 (32.2) \\
\hline$\geq 27$ & $318(19.4)$ & $331(20.0)$ & $82(16.4)$ & $84(16.0)$ \\
\hline No information & $95(5.8)$ & $110(6.6)$ & $35(7.0)$ & $37(7.0)$ \\
\hline \multicolumn{5}{|l|}{ Previous abortions*, $n(\%)$} \\
\hline No & $1438(87.6)$ & $1430(86.2)$ & $423(84.6)$ & 451 (85.9) \\
\hline Yes & $200(12.2)$ & $225(13.6)$ & $74(14.8)$ & 73 (13.9) \\
\hline Missing & $4(0.2)$ & $4(0.2)$ & $3(0.6)$ & $1(0.2)$ \\
\hline \multicolumn{5}{|l|}{ Previous stillbirths, n (\%) } \\
\hline No & $1512(92.1)$ & $1526(92.0)$ & $450(90.0)$ & $476(90.7)$ \\
\hline Yes & $125(7.6)$ & $128(7.7)$ & $47(9.4)$ & $48(9.1)$ \\
\hline Missing & $5(0.3)$ & $5(0.3)$ & $3(0.6)$ & $1(0.2)$ \\
\hline \multicolumn{5}{|l|}{ Previous deliveries, $n(\%)$} \\
\hline None & $478(29.1)$ & $528(31.8)$ & $153(30.6)$ & $171(32.6)$ \\
\hline One & $507(30.9)$ & $508(30.6)$ & $164(32.8)$ & $150(28.6)$ \\
\hline Two & $321(19.5)$ & $299(18.0)$ & 78 (15.6) & 98 (18.7) \\
\hline Three or more & $330(20.1)$ & $320(19.3)$ & $104(20.8)$ & $105(20.0)$ \\
\hline Missing & $6(0.4)$ & $4(0.2)$ & $1(0.2)$ & $1(0.2)$ \\
\hline \multicolumn{5}{|l|}{ HIV status, n (\%) } \\
\hline Negative & $1311(79.8)$ & $1332(80.3)$ & $385(77.0)$ & $424(80.8)$ \\
\hline Positive & $331(20.2)$ & $327(19.7)$ & $115(23.0)$ & 101 (19.2) \\
\hline \multicolumn{5}{|l|}{ Malaria symptoms $†$} \\
\hline Fever, n (\%) & $411(25.0)$ & $408(24.6)$ & $139(27.8)$ & 119 (22.7) \\
\hline Headache, n (\%) & $712(43.4)$ & $717(43.2)$ & $205(41.0)$ & 227 (43.2) \\
\hline Cold/chills, n (\%) & 309 (18.8) & 308 (18.6) & $103(20.6)$ & $98(18.7)$ \\
\hline Vomiting/nausea, n (\%) & $464(28.3)$ & $458(27.6)$ & $148(29.6)$ & $147(28.0)$ \\
\hline Body aches, n (\%) & 365 (22.2) & 371 (22.4) & $122(24.4)$ & 117 (22.3) \\
\hline Self-reported malaria, $\mathrm{n}(\%)$ & $97(5.9)$ & $107(6.4)$ & $28(5.6)$ & $28(5.3)$ \\
\hline Had had malaria test, $n(\%)$ & $120(7.3)$ & $134(8.1)$ & $39(7.8)$ & $30(5.7)$ \\
\hline
\end{tabular}


Estimation of conception date and gestational age at birth

Conception date was estimated using the gestational age at the first visit and visit date. Study nurses had noted the best estimate of gestational length using the date of last menstrual period, uterine fundal height and assumed date of birth. Gestational weeks at birth were estimated from the dates of giving birth (or date of admission to birthplace if the date of birth was lacking) and the estimated conception dates. For women lacking conception dates or birth (admission) dates, the gestational ages at birth were defined as 'missing.'

\section{Data collection}

Study nurses abstracted pregnancy data from women's maternity cards and asked some additional questions related to compliance and symptoms. ${ }^{17} 1820$ Birth data were abstracted by study nurses from maternity cards originally filled by delivery nurses. Delivery nurses were informed of the study and asked to put the birth records of the study women into separate study boxes. Study women were to be identified by the coloured identification cards stapled to the maternity cards. However, separating birth records did not succeed very well and only $2258(52 \%)$ of the birth records were found.

\section{Tracing}

To find the birth data of the 2068 women whose data were missed by the original data collection method, we undertook extensive tracing by applying different methods (described in online supplementary file). Matching of women in admission and birth record books to trial women was made using a combination of probabilistic matching procedures and manual checking of the similarity of the background characteristics of the women (age, parity, name, residence, date of admission/birth, recruitment date). Probability distributions of the matching likelihood were categorised into three levels.

\section{Women's deaths}

We obtained information of all deaths of women aged 15-49 years recorded in Maputo City and neighbouring Matola City civil registration during the period January 2007-April 2010, overall 9670 women. We coded the handwritten cause of death from the death registers before matching to the study women. The 9670 deaths were matched against the trial women in the same way as matching for births, but the probabilities were then categorised into four levels. Manual checking was performed.

For all dead women, a theoretical date of giving birth was calculated: the estimated conception date+280 days. For consistency, this theoretical date was used, even if we had the actual birth date; for those without conception date, the actual birth date, if available, was used. Using the time between the conception date and date of death, women's deaths were classified into: (1) death during pregnancy or $<42$ days postpartum; (2) death during 42-365 days postpartum; (3) combining groups 1 and 2. Three deaths were recorded by the original data collection, ${ }^{17}$ but only one was found in the death register. In the current paper, these three deaths were added to the first group.

\section{Statistical analysis}

Analyses were performed on an intention-to-treat basis. Twin pregnancies ( $\mathrm{n}=48$ pairs) were included in the analysis because their numbers were similar in the two groups and their exclusion did not alter the results. Subgroup analyses were performed for women's death by HIV status, and (in the selective group) by $\mathrm{Hb}$ levels at recruitment and iron tablets given at recruitment. The statistical significance of the differences in continuously distributed birth outcomes were analysed by the two sample Student's t-test, and that of categorical outcomes by Pearson $\chi^{2}$ test or Fisher's exact test (if cells contained $<5$ cases). Statistical significance was set at $\mathrm{p}<0.05$.

Generalised linear models were used to estimate the risk ratios (RR with 95\% CIs) of the effect of the intervention on binary birth outcomes (low birth weight, preterm birth, caesarean section delivery, perinatal death, women's death). To estimate the effect of iron group on birth outcomes, we undertook: (1) a complete case analysis (ie, analysis of combined data collected by original data collection and those traced); (2) by multiple imputation (ie, imputing data for birth outcomes missed using the original data collection method before tracing); and (3) by analysing different scenarios of matching the traced outcome data to the trial women. The multiple imputation (20 imputed data sets) was undertaken using the multivariate normal model as described by Little and Rubin. ${ }^{21}$ The interaction between the assigned intervention group and gestational age at enrolment (as a continuous variable) was studied. The interaction measured how much the risk of outcomes in the selective group as compared to the routine group changed by each additional week in the timing of enrolling into the study. Stata V.11 statistical software was used for all analyses.

\section{RESULTS}

Birth data were available for $3301(76 \%)$ of the 4326 pregnant women: $2258(52 \%)$ were retrieved by the original collection method and $1043(24 \%)$ by tracing (figure 1 and table 1). In both iron supplementation groups, about a fifth of women having birth data were HIV-positive at recruitment. In the selective group, 32\% of women had $\mathrm{Hb}$ below $9 \mathrm{~g} / \mathrm{dL}$ at recruitment and were given iron treatment (table 1). Likewise, in subsequent visits, $34 \%-27 \%$ of visiting women in the selective group received iron treatment. In the routine group, practically everyone visiting received iron prophylaxis. ${ }^{17}$ Women with birth data started prenatal consultations slightly later (mean gestational weeks at enrolment 21.6, SD 5.8) than those without birth data (mean 20.6, SD 


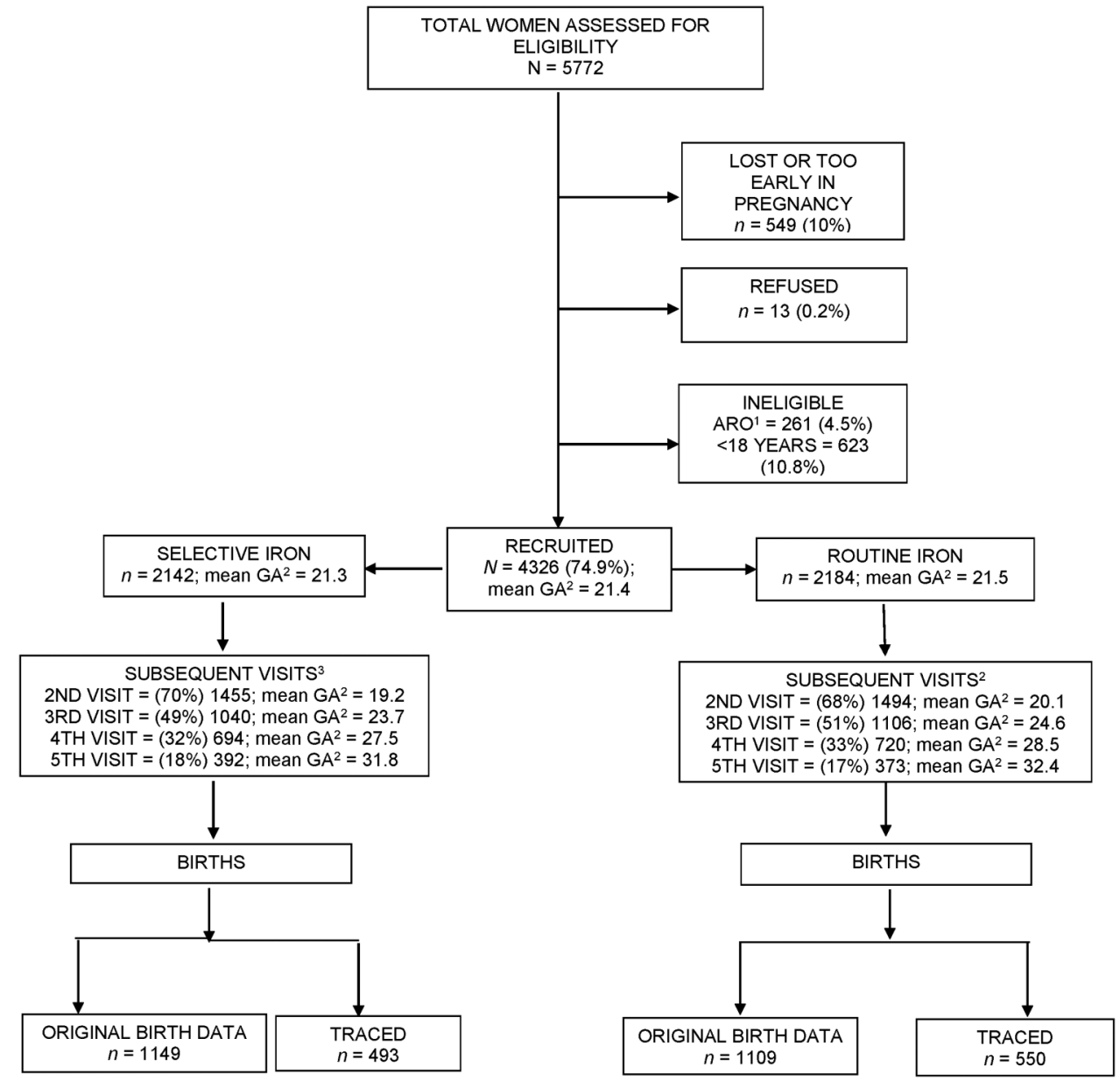

Figure 1 PROFEG trial flow diagram. ${ }^{1} \mathrm{ARO}$, high-risk pregnancy; ${ }^{2} \mathrm{GA}$, gestational age in weeks; ${ }^{3}$ After recruitment, $\%$ were calculated from recruited, $\mathrm{n}=4326$.

6.0) ( $p<0.001)$; the two groups did not differ with regard to other background characteristics.

The $\mathrm{Hb}$ values in table 1 were received by the Hemocue method. Since Lovibond was routinely used in Maputo health centres at the first prenatal visit, we could compare the two $\mathrm{Hb}$ measurement methods in the selective group (see online supplementary table). Lovibond identified anaemia much less as it consistently gave higher $\mathrm{Hb}$ values than Hemocue. Cross-tabulating Hemocue and Lovibond measurements showed that $97 \%$ of the 308 women with $\mathrm{Hb}$ below $9 \mathrm{~g} / \mathrm{dL}$ with the Hemocue method had $\mathrm{Hb} 9 \mathrm{~g} / \mathrm{dL}$ or more and $47 \%$ had $12 \mathrm{~g} / \mathrm{dL}$ or more with the Lovibond method (see online supplementary file).

Availability of birth data did not differ between the iron groups $(77 \%$ vs $76 \%$, table 2). Birth outcomes were similarly distributed between the two groups. Table 3 compares birth outcomes taking into account the goodness of matching of traced women and lacking information. Overall, the results were comparable between the two groups.

Even though the birth outcomes were similarly distributed between the two iron supplementation groups, there was a difference in regard to the data collection method (table 2). Those retrieved with the original method were more likely to experience perinatal death compared to those traced (3.2\% vs $0.7 \%$; $\mathrm{p}<0.001)$; have a shorter gestational length (38.4, SD 4.5 vs 40.1, SD 7.7, $\mathrm{p}<0.001$ ); have a higher birth weight (mean 2996 g, SD 505 vs 2941 g, SD $598, \mathrm{p}<0.001$ ); and to be less likely to be delivered through caesarean section $(1.6 \%$ vs $9.9 \%, \mathrm{p}<0.001)$.

The two iron groups were similar with regard to symptoms suggestive of malaria during pregnancy (fever, headache, cold/chills, nausea/vomiting and body aches) and complications during labour. ${ }^{18}$ There was a suggestion of increased incidence of self-reported malaria during pregnancy in the routine group (OR 1.37, 95\% CI 0.98 to 1.92 ), fetal heartbeat not heard at labour and more likelihood of a longer hospital stay after birth. ${ }^{18}$ All these differences were, however, statistically nonsignificant. Less than half of the women received malaria prophylaxis with SP in the recruitment visit. In the two subsequent visits, the proportions were higher, but not all women visited (see online supplementary file). In none of the time points were there differences between the two iron supplementation groups.

Table 4 presents the deaths of the study women as estimated from record linkage to death registers, overall and 
Table 2 Birth outcomes by trial group and by the data collection method, numbers (proportions \%) or means (SDs SD)

\begin{tabular}{|c|c|c|c|c|c|c|c|}
\hline \multirow[b]{2}{*}{ Birth outcomes } & \multicolumn{3}{|c|}{ Original+traced birth data $(n=3301)$} & \multicolumn{2}{|c|}{ Original birth data $(n=2258)$} & \multicolumn{2}{|c|}{ Traced birth data $(n=1043)$} \\
\hline & $\begin{array}{l}\text { Selective iron } \\
(n=1642)\end{array}$ & $\begin{array}{l}\text { Routine iron } \\
(n=1659)\end{array}$ & p Value & $\begin{array}{l}\text { Selective iron } \\
(n=1149)\end{array}$ & $\begin{array}{l}\text { Routine iron } \\
(n=1109)\end{array}$ & $\begin{array}{l}\text { Selective iron } \\
(n=493)\end{array}$ & $\begin{array}{l}\text { Routine iron } \\
(n=550)\end{array}$ \\
\hline (\% of recruited) & $(76.7)$ & $(76.0)$ & & $(53.6)$ & $(50.8)$ & $(23.0)$ & $(25.2)$ \\
\hline \multicolumn{8}{|l|}{ Duration of gestation*, n (\%) } \\
\hline$<37$ weeks & $445(27.1)$ & $419(25.3)$ & & $304(26.5)$ & $274(24.7)$ & $141(28.6)$ & $145(26.4)$ \\
\hline$\geq 37$ weeks & 1197 (72.9) & $1240(74.7)$ & 0.193 & $845(73.5)$ & $835(75.3)$ & $352(71.4)$ & 405 (73.6) \\
\hline Duration of gestation*, mean (SD) weeks & $38.9(5.7)$ & $39.1(5.8)$ & 0.302 & $38.4(4.5)$ & $38.5(4.3)$ & $40.1(7.7)$ & $40.3(7.9)$ \\
\hline Birth weight $(\mathrm{g}), \mathrm{n}(\%)$ grams & & & 0.072 & & & & \\
\hline$<2500$ & $181(11.0)$ & $189(11.7)$ & & $134(11.7)$ & $142(12.8)$ & $47(9.5)$ & $47(8.5)$ \\
\hline 2500-2999 & $421(25.6)$ & $416(25.0)$ & & $351(30.5)$ & $345(31.1)$ & $70(14.2)$ & $71(12.9)$ \\
\hline 3000-3499 & $552(33.6)$ & $513(30.9)$ & & $465(40.5)$ & $419(37.8)$ & $87(17.6)$ & $94(17.1)$ \\
\hline 3500-3999 & $183(11.1)$ & $198(11.9)$ & & $146(12.7)$ & $153(13.8)$ & $37(7.5)$ & $45(8.2)$ \\
\hline$\geq 4000$ & $45(2.7)$ & $29(1.7)$ & & $34(3.0)$ & $23(2.1)$ & $10(82.0)$ & $6(1.1)$ \\
\hline $\bar{N}$ o information & $260(15.8)$ & $314(18.8)$ & & $19(1.7)$ & $27(2.4)$ & $242(49.1)$ & $287(52.2)$ \\
\hline $\begin{array}{l}\text { Birth weight, mean } \\
\text { (SD) grams }\end{array}$ & $2993.1(514.2)$ & $2977.6(534.3)$ & 0.462 & $3001.3(494.7)$ & $2989.4(514.9)$ & $2952.6(591.1)$ & $2929.2(606.1)$ \\
\hline Mode of delivery, $\mathrm{n}(\%)$ & & & 0.775 & & & & \\
\hline Normal & $1115(67.9)$ & $1130(68.1)$ & & 1007 (87.6) & $991(89.4)$ & $108(21.9)$ & $139(25.3)$ \\
\hline Caesarean section & $66(4.0)$ & $74(4.5)$ & & $15(1.3)$ & $22(2.0)$ & $51(10.3)$ & $52(9.5)$ \\
\hline No information & $461(28.1)$ & $455(27.4)$ & & $127(11.1)$ & $96(8.7)$ & $334(67.7)$ & $359(65.3)$ \\
\hline Perinatal deathst, n (\%) & $39(2.4)$ & $40(2.4)$ & 0.946 & $35(3.0)$ & 37 (3.3) & $4(0.8)$ & $3(0.5)$ \\
\hline
\end{tabular}


Table 3 Comparison of the two iron groups ${ }^{*}$ in regard to birth outcomes, by the data collection method and goodness of matching, risk ratios $(\mathrm{RR}, 95 \% \mathrm{Cls})$

\begin{tabular}{|c|c|c|c|c|c|}
\hline \multirow[b]{2}{*}{ Outcomes } & \multirow[b]{2}{*}{$\begin{array}{l}\text { Original birth } \\
\text { data }(n=2258) \\
R R(95 \% \mathrm{Cl})\end{array}$} & \multicolumn{3}{|c|}{ Goodness of matching } & \multirow[b]{2}{*}{$\begin{array}{l}\text { Multiple } \\
\text { imputation } \\
\text { model† } \\
\text { RR }(95 \% \mathrm{Cl}) \\
\end{array}$} \\
\hline & & $\begin{array}{l}\text { Original birth data } \\
\text { +Best matching } \\
\text { ( } \mathrm{n}=2522) \mp \\
\text { RR }(95 \% \mathrm{Cl})\end{array}$ & $\begin{array}{l}\text { Original birth data } \\
\text { +Second best } \\
\text { matching }(n=2786) \neq \\
\operatorname{RR}(95 \% \mathrm{Cl})\end{array}$ & $\begin{array}{l}\text { Original birth data } \\
\text { +Least likely } \\
\text { matching }(n=3294) \ddagger \\
\text { RR }(95 \% \mathrm{Cl})\end{array}$ & \\
\hline $\begin{array}{l}\text { Preterm birth } \\
\text { (<37 weeks) }\end{array}$ & 1.09 (0.90 to 1.32$)$ & $1.04(0.91$ to 1.19$)$ & $1.04(0.92$ to 1.18$)$ & $1.08(0.97$ to 1.21$)$ & 1.09 (0.93 to 1.27$)$ \\
\hline $\begin{array}{l}\text { Low birth } \\
\text { weight } \\
(<2500 \mathrm{~g})\end{array}$ & $0.89(0.69$ to 1.15$)$ & $0.88(0.71$ to 1.11$)$ & $0.90(0.73$ to 1.11$)$ & $0.93(0.77$ to 1.12$)$ & $0.96(0.70$ to 1.18$)$ \\
\hline $\begin{array}{l}\text { Cesarean } \\
\text { section } \\
\text { delivery }\end{array}$ & $0.65(0.34$ to 1.27$)$ & $0.82(0.49$ to 1.36$)$ & $0.92(0.61$ to 1.39$)$ & $0.90(0.65$ to 1.25$)$ & $0.69(0.36$ to 1.34$)$ \\
\hline $\begin{array}{l}\text { Perinatal } \\
\text { death }\end{array}$ & $0.91(0.57$ to 1.46$)$ & $0.92(0.59$ to 1.45$)$ & $0.95(0.61$ to 1.49$)$ & $0.99(0.64$ to 1.53$)$ & 0.90 (0.45 to 1.80$)$ \\
\hline
\end{tabular}

by the goodness of matching. Women's deaths during pregnancy or $<42$ days postpartum were more common in the selective group among the best and second best matched women (RR 2.30, 95\% CI 1.00 to 5.27) and among all women (RR 1.86, 95\% CI 1.03 to 3.35).

HIV/AIDS was the most common cause of death in both iron supplementation groups, and it was more common in the selective than in the routine group (table 5). Otherwise, the causes were similar in the two groups. Anaemia and pregnancy-related reasons were not common. Causes which were not clear (either an unknown abbreviation was used, or handwriting was not readable) were the second most common cause of death ( $24 \%$ and $21 \%$ ). If all deaths up to 365 days postpartum, regardless of the goodness of matching, were inspected, all extra deaths in the selective group had an HIV/ AIDS-related cause; this was not the case when the two best matched groups were inspected (table 5).

In subgroup analyses, number of deaths in the selective group did not differ by $\mathrm{Hb}$ levels or iron therapy recommendation at recruitment (data not shown). By HIV-status at recruitment, deaths occurred differently in

Table 4 Comparison of women's deaths in the selective iron group to the routine iron group, overall and by the probability score of matching in the death register, numbers (\%) of deaths and risk ratios (RR, $95 \% \mathrm{Cls} \mathrm{Cl}$ )

\begin{tabular}{|c|c|c|c|c|c|c|}
\hline & \multicolumn{6}{|c|}{ Goodness of matching trial women to death registers* } \\
\hline & \multicolumn{2}{|c|}{$\begin{array}{l}\text { Best and second best } \\
\text { matching }\end{array}$} & \multicolumn{2}{|c|}{$\begin{array}{l}\text { Best, second best and } \\
\text { third best matching }\end{array}$} & \multicolumn{2}{|c|}{ All matched women } \\
\hline & $\begin{array}{l}\text { Selective } \\
\text { iron } \\
\mathrm{n}(\%)\end{array}$ & $\begin{array}{l}\text { Routine } \\
\text { iron } \\
\text { n (\%) }\end{array}$ & $\begin{array}{l}\text { Selective } \\
\text { iron } \\
\mathrm{n}(\%)\end{array}$ & $\begin{array}{l}\text { Routine } \\
\text { iron } \\
\text { n (\%) }\end{array}$ & $\begin{array}{l}\text { Selective } \\
\text { iron } \\
\mathrm{n}(\%)\end{array}$ & $\begin{array}{l}\text { Routine } \\
\text { iron } \\
\mathbf{n}(\%)\end{array}$ \\
\hline $\begin{array}{l}\text { Death of woman during pregnancy or } \\
<42 \text { days postpartum }\end{array}$ & $18(0.8)$ & $8(0.37)$ & $25(1.2)$ & $14(0.6)$ & $31(1.4)$ & $17(0.8)$ \\
\hline Death of woman $42-365$ days postpartum & $57(2.7)$ & $52(2.4)$ & $78(3.6)$ & $74(3.4)$ & $92(4.3)$ & $87(4.0)$ \\
\hline $\begin{array}{l}\text { Death of woman during pregnancy or up } \\
\text { to } 365 \text { days postpartum }\end{array}$ & $75(3.5)$ & $60(2.7)$ & $103(4.8)$ & $88(4.0)$ & $123(5.7)$ & $104(4.8)$ \\
\hline $\begin{array}{l}\text { Death of woman during pregnancy or } \\
<42 \text { days postpartum R } \mathrm{R} \dagger\end{array}$ & \multicolumn{2}{|c|}{$2.30(1.00-5.27)$} & \multicolumn{2}{|c|}{$1.82(0.95-3.49)$} & \multicolumn{2}{|c|}{$1.86(1.03-3.35)$} \\
\hline $\begin{array}{l}\text { Death of woman } 42-365 \text { days postpartum } \\
\text { RR }\end{array}$ & \multicolumn{2}{|c|}{$1.12(0.77-1.62)$} & \multicolumn{2}{|c|}{$1.07(0.79-1.47)$} & \multicolumn{2}{|c|}{$1.08(0.81-1.44)$} \\
\hline $\begin{array}{l}\text { Death of woman during pregnancy or up } \\
\text { to } 365 \text { days postpartumRR } \dagger\end{array}$ & \multicolumn{2}{|c|}{$1.28(0.91-1.78)$} & \multicolumn{2}{|c|}{$1.19(0.90-1.57)$} & \multicolumn{2}{|c|}{$1.21(0.94-1.55)$} \\
\hline
\end{tabular}


Table 5 Causes of death during pregnancy and first year, by time and iron group in the two best matching groups, and all women by iron group

\begin{tabular}{|c|c|c|c|c|c|c|c|c|c|c|}
\hline \multirow[b]{3}{*}{$\begin{array}{l}\text { Causes of } \\
\text { death }\end{array}$} & \multicolumn{4}{|c|}{$\begin{array}{l}\text { Death during pregnancy or }<42 \text { days } \\
\text { postpartum }\end{array}$} & \multicolumn{4}{|c|}{ Death $42-365$ days postpartum } & \multirow{2}{*}{\multicolumn{2}{|c|}{$\begin{array}{l}\text { All deaths }{ }^{\star} \text { during } \\
\text { pregnancy or up } \\
\text { to } 365 \text { days } \\
\text { postpartum }\end{array}$}} \\
\hline & \multicolumn{2}{|l|}{ Best } & \multicolumn{2}{|c|}{ Second best } & \multicolumn{2}{|l|}{ Best } & \multicolumn{2}{|c|}{ Second best } & & \\
\hline & $\begin{array}{l}\text { Selective } \\
\text { iron }\end{array}$ & $\begin{array}{l}\text { Routine } \\
\text { iron }\end{array}$ & $\begin{array}{l}\text { Selective } \\
\text { iron }\end{array}$ & $\begin{array}{l}\text { Routine } \\
\text { iron }\end{array}$ & $\begin{array}{l}\text { Selective } \\
\text { iron }\end{array}$ & $\begin{array}{l}\text { Routine } \\
\text { iron }\end{array}$ & $\begin{array}{l}\text { Selective } \\
\text { iron }\end{array}$ & $\begin{array}{l}\text { Routine } \\
\text { iron }\end{array}$ & $\begin{array}{l}\text { Selective } \\
\text { iron }\end{array}$ & $\begin{array}{l}\text { Routine } \\
\text { iron }\end{array}$ \\
\hline HIV/AIDS & 2 & 1 & 3 & 1 & 7 & 4 & 11 & 11 & 50 & 31 \\
\hline Tuberculosis & 0 & 1 & 0 & 0 & 3 & 1 & 1 & 1 & 6 & 9 \\
\hline Malaria & 1 & 0 & 0 & 0 & 0 & 0 & 0 & 1 & 4 & 4 \\
\hline Anaemia & 0 & 0 & 0 & 0 & 0 & 2 & 2 & 1 & 5 & 4 \\
\hline $\begin{array}{l}\text { Other } \\
\text { infection }\end{array}$ & 1 & 0 & 0 & 1 & 2 & 3 & 2 & 5 & 11 & 16 \\
\hline $\begin{array}{l}\text { Pregnancy- } \\
\text { related }\end{array}$ & 2 & 0 & 2 & 1 & 2 & 3 & 0 & 1 & 6 & 5 \\
\hline Trauma & 0 & 0 & 1 & 0 & 1 & 2 & 0 & 0 & 4 & 5 \\
\hline $\begin{array}{l}\text { Other } \\
\text { diseases }\end{array}$ & 1 & 1 & 0 & 0 & 3 & 1 & 1 & 4 & 6 & 7 \\
\hline Not clear & 2 & 0 & 1 & 2 & 11 & 4 & 10 & 7 & 29 & 22 \\
\hline $\begin{array}{l}\text { No } \\
\text { information }\end{array}$ & 2 & 0 & 0 & 0 & 0 & 0 & 0 & 1 & 2 & 1 \\
\hline Total deaths & 11 & 3 & 7 & 5 & 28 & 20 & 27 & 32 & 123 & 104 \\
\hline
\end{tabular}

the two iron supplementation groups, and all extra deaths in the selective group occurred among HIV-negative women. However, the numbers of deaths were small in each subgroup, and none of the differences were statistically significant.

When we excluded women recruited at $\geq 36$ week's gestation $(n=24)$ and those missing gestation age at recruitment $(n=277)$, the birth outcome results did not substantially change. The death rate during pregnancy and $<42$ days postpartum remained higher in the selective group, but risk ratios became statistically non-significant (data not shown). When we studied the interaction between the iron supplementation groups and gestational age at enrolment, we found no statistically significant interaction in regard to birth outcomes ( $p$ values ranged between 0.131 and 0.959 ). The $p$ values of the interaction in regard to women's deaths also were statistically non-significant, except in two cases with a borderline significance $(p=0.056)$. In the selective group (compared to the routine group), the risk of death during pregnancy or $<42$ days postpartum increased by each additional week in enrolling into the study (RR 1.12, 95\% CI 1.00 to $1.26)$, and the risk during pregnancy or $\leq 365$ days postpartum RR was 1.06 (95\% CI 1.00 to 1.13) (data not shown).

\section{DISCUSSION}

Results reported in this paper, as well as previously, ${ }^{18}$ showed that two policies of giving iron to pregnant women, either as routine supplementation to everyone or treating only women with low $\mathrm{Hb}$, had similar health outcomes during pregnancy and at birth. There were some small differences favouring one of the groups, but none of these differences were statistically significant. However, women's deaths during pregnancy and $<42$ days postpartum suggested a worse outcome in the selective iron group. There were various inaccuracies in outcome data collection, but they should have been comparable in both groups, giving unbiased though inaccurate results. The results nevertheless did not change when evaluated using multiple imputation of birth outcomes.

The lack of strong differences in birth outcomes between selective and routine iron prophylactic groups, which were similar when we undertook complete case analysis, analysis by tracing mechanisms and multiple imputations, gives confidence that these results may not have changed if all birth outcomes were ascertained using the original data collection method. Our findings are comparable with the results of some previous studies undertaken in malaria-endemic low-income settings, which showed no effect of iron prophylaxis on child outcomes, ${ }^{92-24}$ but in contrast with other studies that have shown some benefits of iron supplementation..$^{1025}{ }^{26} \mathrm{In}$ our study, two iron policies were compared, while previous studies have compared iron supplementation versus no supplementation. A recent meta-analysis found that while iron supplementation decreased the risk of anaemia and low birth weight, it had no effect on other birth outcomes. ${ }^{8}$ That study, however, included studies undertaken in different countries, not stratified by whether malaria was endemic. Thus, there still is paucity 
of data of iron prophylaxis in regard to maternal and child outcomes and the impact of various environments is not clear.

A common opinion is that in malaria-endemic areas, iron prophylaxis during pregnancy should not be given without malaria prophylaxis. ${ }^{9}$ In our trial setting, malaria prophylaxis was the recommendation, but high coverage was unlikely (see online supplementary file). However, it seems to have been more common in the more rural than urban health centres. There was no difference in regard to the iron supplementation group.

Matching of the study women to death registers revealed more deaths in the selective iron group, compared to the routine group. In subgroup analyses of the selective group, the death rates were not different by $\mathrm{Hb}$ level measured at recruitment or consecutive (therapeutic) iron supplementation. If the lack of iron was the reason for more deaths in the selective group, there should have been more deaths in the low $\mathrm{Hb}$ women, but this was not the case. On the other hand, the women with low $\mathrm{Hb}$ were given a higher dose of iron than the women in the routine group, which confuses the issue, as large doses could have been harmful. The dose of folic acid was higher in the selective group, which could have been harmful, ${ }^{27}$ a possibility which we did not consider at the time we planned the study. Another possible reason, although we think it to be unlikely, could result from the uncertainty in matching the trial women to the death register.

Neither did the cause of death suggest reasons for this unexpected finding of more deaths. HIV infection could have been a confounder or a modifier in regard to deaths. In theory, it is possible that varying iron treatment in the two groups led to different ways of administering HIV treatment, but we have no data supporting it. Likewise, the possibility of repeated $\mathrm{Hb}$ measurement increasing HIV spread is a theoretical possibility, but we have no evidence that the hygienic rules of using Hemocue were not followed. We think that the most likely reasons for extra deaths in the selective group were a chance finding. The positive interaction of gestation age at enrolment to extra deaths, that is, the later a woman arrived, the more likely the extra deaths in the selective group, supports the chance finding.

As far as we are aware, this is by far the largest trial assessing the effectiveness of prenatal prophylactic iron on maternal and child health in malaria-endemic and HIV-prevalent settings. Strength is the comparability of the groups due to randomisation and the large number of participants. Results are generalisable to the local prenatal care; since the trial was made in real circumstances, it included most women entering the care sites, and it allowed treatment of anaemia. Both with regard to the compliance of nurses to the trial protocol and women's reported uptake of iron and folic acid tablets, we achieved adequate adherence. ${ }^{17} 1820$

There were a number of limitations, including relatively weak interventions, unknown accuracy of data and loss to follow-up. Women in Maputo enter prenatal care late, and thus our trial is on iron prophylaxis starting in mid-pregnancy or late pregnancy, and does not inform of iron supplementation starting in early pregnancy. Many women had only a few visits after the recruitment visit, and the compliance of non-visitors is unknown. They may have visited other health centres, have no visits or bought iron tablets by themselves. Some collected data were inaccurate due to inherent problems of measures, such as gestation age or due to poor recording in our data sources, such as perinatal deaths. Low intervention intensity and inaccuracies in measurement tend to diminish true differences between the groups, artificially leading to a 'no difference' conclusion.

We could collect birth data with our original data collection method only for half of the women. By using available registers and telephone calls to women, follow-up could be improved, and we obtained $76 \%$ of the birth data. In regard to mothers' death, we had a relatively complete source in death registers coverage estimated to be at least $85 \%$. However, the traced birth data were less complete than the data by the original data collection method. Of those untraced, we assume that the most common reason was self-referral to higher level hospitals, where study women's births were lost among many other births. Some women gave birth at home (estimated $10 \%$ of all women) or had late miscarriages (no estimate of the numbers), and data from these women were not readily available from health centre records.

A particular problem was that all birth records, which usually were large books containing information of all admissions and/or births over several weeks or months, were not valued after they were completed. They were not properly stored and they could be borrowed by students who might not return them. Consequently, at the time of retrospective data collection, some of them could not be found. Poor archiving was true also for electronic data, and technical problems were common.

Identifying the study women by record linkages was a challenge. There was no unique identification number and names were written in a variety of ways. The records were handwritten and often filled out in a hurry, making them susceptible to mistakes. The probabilistic matching strategy we applied was able to overcome some of the problems, but still the matching may contain uncertainties.

Our experiences in this trial demonstrate challenges in the follow-up of participants in large-scale prenatal trials in low-income settings. Apparently, the problem we faced with missing births and tracing would have been reduced if we had better prior knowledge of the problem; thus, we would have improved the trial design and built different or additional data collection strategies. It would have been good to put more effort to map in detail the routines and data collection practices in the local care facilities. Our experience also suggests that either only outside data collectors should have been used or the incentives to the routine care nurses should 
have been built to better encourage data gathering, for example, by paying per collected data.

\section{CONCLUSIONS}

We found that in this malaria-endemic and HIVprevalent low-income setting, routine and selective iron prophylaxis during pregnancy were largely comparable with regard to birth outcomes, but more women might have died during pregnancy or early postpartum in the selective iron supplementation group. Taking into account the low price of iron medication, the problems of reliable routine measurement of $\mathrm{Hb}^{28-30}$ and the logistic simplicity of routine iron supplementation, we recommend routine iron prophylaxis during pregnancy in Maputo city and similar areas until further data accumulate and better $\mathrm{Hb}$ and iron status measurement tools are available. This recommendation concerns iron prophylaxis started in mid-pregnancy or late pregnancy and assumes that malaria prophylaxis is in place. However, taking into account that iron deficiency is only one of the causes of anaemia and the growing concern that iron supplementation is associated with increased risk of infections, more large-scale studies are needed in malaria-endemic and high HIV-prevalence low-income settings.

\section{Author affiliations}

${ }^{1}$ Health Services and Policy Research, National Institute for Health and Welfare, Helsinki, Finland

${ }^{2}$ Centre for Medical Informatics, Usher Institute of Population Health Sciences and Informatics, The University of Edinburgh, UK

${ }^{3}$ School of Health Sciences, University of Tampere, Tampere, Finland

${ }^{4}$ Medical Faculty, Department of Physiological Sciences, Eduardo Mondlane University, Maputo, Mozambique

${ }^{5}$ Medical Faculty, Department of Community Health, Eduardo Mondlane University, Maputo, Mozambique

${ }^{6}$ Ministry of Health, Maputo, Mozambique

Acknowledgements The study was funded by two grants from the Academy of Finland (2004: 210631; 2010: 139191).

Contributors EH designed and is responsible for the conception of the PROFEG Trial. EH, BIN and SP designed, analysed and wrote the paper. $B C, B I N, C S, E R, G S, J C, M D, O A$ and SP participated in the planning of the PROFEG Trial and made substantial contribution in its execution and participated in interpretation of results and critically reviewing the manuscript. $E R$ and $O A$ were responsible for data preparation and cleaning.

Funding The study was funded by two grants from the Academy of Finland (2004: 210631; 2010: 139191).

Competing interests None declared.

Patient consent Obtained.

Ethics approval Mozambique Ministry of Health Ethics Committee (CNBS (Ref. 84/CNBS/06)) and Eduardo Modlane University Medical Faculty Ethics Board (25 January 2006).

Provenance and peer review Not commissioned; externally peer reviewed.

Data sharing statement Statistical codes and the data set are available from the corresponding author bright.nwaru@uta.fi. Informed consent was not obtained for data sharing, but the presented data are anonymised and risk of identification is low. No extra data are available until 2017.

Open Access This is an Open Access article distributed in accordance with the Creative Commons Attribution Non Commercial (CC BY-NC 4.0) license, which permits others to distribute, remix, adapt, build upon this work noncommercially, and license their derivative works on different terms, provided the original work is properly cited and the use is non-commercial. See: http:// creativecommons.org/licenses/by-nc/4.0/

\section{REFERENCES}

1. Stoltzfus R, Dreyfuss M. Guidelines for the use of iron supplements to prevent and treat iron deficiency anaemia. ILSI Press, 1998.

2. World Health Organization. Micronutrient deficiencies: iron deficiency anaemia. http://www.who.int/nutrition/topics/ida/en/

3. World Health Organization. The prevalence of anaemia in women: a tabulation of available information (WHO/MCH/MSM/92). 2nd edn. WHO, Maternal Health and Safe Motherhood Programme, Division of Family Health, 1992.

4. Lao TT, Tam KF, Chan LY. Third trimester iron status and pregnancy outcome in non-anaemic women: pregnancy unfavourably affected by maternal iron excess. Hum Reprod 2000;15:1843-8.

5. Yip R. Significance of an abnormally low or high hemoglobin concentration during pregnancy: special consideration of iron nutrition. Am J Clin Nutr 2000;72(Suppl):272S-9S.

6. Peña-Rosas JP, Viteri FE. Effects and safety of preventive oral iron or iron+folic acid supplementation for women during pregnancy. Cochrane Database Syst Rev 2009, (4):CD004736.

7. Villar J. Merialdi M, Gulmezoglu AM, et al. Nutritional interventions during pregnancy for the prevention or treatment of maternal mortality and preterm delivery: an overview of randomized controlled trials. J Nutr 2003;133:1606-25.

8. Haider BA, Olofin I, Wang M, et al. Anaemia, prenatal iron use, and risk of adverse pregnancy outcomes: systematic review and meta-analysis. BMJ 2013;346:f3443.

9. Etheredge AJ, Premij Z, Gunaratna NS, et al. Iron supplementation in iron-replete nonanemic pregnant women in Tanzania: a randomized clinical trial. JAMA Pediatr 2015;169:947-55.

10. Mwangi MN, Roth JM, Smit MR, et al. Effect of daily antenatal iron supplementation plasmodium infection in Kenyan women: a randomized clinical trial. JAMA 2015; 314: 1009-20.

11. Oppenheimer SJ. Iron and its relation to immunity and infectious disease. J Nutr 2001;131:616S-35S.

12. Prentice AM. Iron metabolism, malaria, and other infections: what is all the fuss about? J Nutr 2008;138:2537-41.

13. Gera T, Sachdev HP. Effect of iron supplementation on incidence of infectious illness in children: systematic review. BMJ 2002;325:1142.

14. Lawn JE, Cousens S, Zupan J, Lancet Neonatal Survival Steering Team. 4 million neonatal deaths: when? Where? Why? Lancet 2005;365:891-900.

15. Idemyor V. Human immunodeficiency virus (HIV) and malaria interaction in sub-Saharan Africa: the collision of two titans. HIV Clin Trials 2007:8:246-53.

16. Sazawal S, Black RE, Ramsan M, et al. Effects of routine prophylactic supplementation with iron and folic acid on admission to hospital and mortality in preschool children in a high malaria transmission setting: community-based, randomized, placebo-controlled trial. Lancet 2006;367:133-43.

17. Nwaru BI, Parkkali S, Abacassamo F, et al. A pragmatic randomised controlled trial on routine iron prophylaxis during pregnancy in Maputo, Mozambique (PROFEG): rationale, design, and success. Matern Child Nutr 2015;11:146-63.

18. Parkkali S, Abacassamo F, Nwaru BI, et al. Comparison of routine prenatal iron prophylaxis and screening and treatment for anaemia: pregnancy results and preliminary birth results from a pragmatic randomized controlled trial (PROFEG) Maputo Mozambique. BMJ Open 2013;3:e001948.

19. Dgedge M. Implementation of an insecticide Bednet programme for malaria prevention through the primary health care system in Mozambique [Doctoral thesis]. London School of Hygiene and Tropical Medicine, 2000.

20. Nwaru BI, Salomé G, Abacassamo F, et al. Adherence in a pragmatic randomized controlled trial on prophylactic iron supplementation during pregnancy in Maputo, Mozambique. Public Health Nutr 2015;18:1127-34.

21. Little RJA, Rubin DB. Statistical analysis with missing data. 2nd edn Hoboken, NJ: Wiley-InterScience, 2002.

22. Fleming AF, Ghatoura GB, Harrison KA, et al. The prevention of anaemia in pregnancy in primigravidae in the Guinea savanna of Nigeria. Ann Trop Med Parasitol 1986;80:211-33.

23. Ndyomugyenyi R, Magnussen P. Chloroquine prophylaxis, iron/ folic-acid supplementation or case management of malaria attacks in primigravidae in western Uganda: effects on congenital malaria and 
infant haemoglobin concentrations. Ann Trop Med Parasitol 2000;94:759-70.

24. Juncker T, Ameer S, Mmaum A, et al. A trial of iron and folate supplementation during pregnancy in Bangladesh. Atlanta, USA Abstract presented at the American Public Health Association, 2001.

25. Menendez C, Todd J, Alonso PL, et al. The effects of iron supplementation during pregnancy, given by traditional birth attendants, on the prevalence of anaemia and malaria. Trans $R$ Soc Trop Med Hyg 1994;88:590-3.

26. Preziosi P, Prual A, Galan P, et al. Effect of iron supplementation on the iron status of pregnant women: consequences for newborns. Am J Clin Nutr 1997;66:1178-82.
27. Choi JH, Yates Z, Veysey M, et al. Contemporary issues surrounding folic acid fortification initiatives. Prev Nutr Food Sci 2014;19:247-60.

28. Stone JE, Simmons WK, Jutsum PJ, et al. An evaluation of methods of screening for anaemia. Bull World Health Organ 1984;62:115-20.

29. Van Lerberghe W, Keegels G, Cornelis G, et al. Haemoglobin measurement: the reliability of some simple techniques for use in a primary health care setting. Bull World Health Organ 1983;61:957-65.

30. Srivastava T, Negandhi H, Neogi SB, et al. Methods for Hemoglobin Estimation: a review of "What Works". $J$ Hematol Transfus 2014;2:1028. 